\title{
PERSPECTIVE
}

\section{Facial laser surgery}

\section{Shree Harsh", Surendra B. Patil}

Department of Plastic and Maxillofacial Surgery, Government Medical College and Hospital, Nagpur, India

\begin{abstract}
Lasers have a number of clinical applications on the face, ranging from aesthetic uses such as the rejuvenation of ageing face to functional ones such as the correction of bleeding vascular malformations. The vast growing uses of lasers on the face emphasises the need to have knowledge of the subject. Though the vast spectrum of lasers is very difficult to compile in an article, the authors give an overview of the application of lasers in the facial region and discuss the most defining treatment of the individual disease processes.

Keywords: face; laser; surgery

Citation: Harsh S and Patil SB. Facial laser surgery. J Surg Dermatol 2022; 7(1): 137; http://dx.doi.org/10.18282/ jsd.v7.i1.137.
\end{abstract}

*Correspondence to: Shree Harsh, Department of Plastic Surgery, G.MC Nagpur, India; s007harsh@gmail.com

Received: $29^{\text {th }}$ July 2021; Accepted: $23^{\text {rd }}$ September 2021; Published Online: $1^{\text {st }}$ October 2021

\section{Introduction}

\section{Background and history}

Laser is an abbreviation for "light amplification by stimulated emission of radiation". It generates light energy in the photon beam form. The concepts to build laser was postulated in 1917 by Albert Einstein, which was published in The Quantum Theory of Radiation. Maser, an acronym for microwave amplification by stimulated emission of radiation, was devised by Charles $\mathrm{H}$ Townes and Arthur L Schalow in 1958. Townes along with Aleksandr Mikhailovich Prokhorov and Nikolay G Basov were awarded Nobel Prize in 1964 for their contribution in quantum electronics which helped in the discovery of Laser and Maser ${ }^{[1]}$.

Helium-neon laser, the first gas laser which produced a continuous beam, was developed by physicists William Bennett and Ali Javan in 1961. Argon laser was thereafter discovered, followed by 10,600-nm carbon dioxide $\left(\mathrm{CO}_{2}\right)$ laser by engineers Kumar Patel et al. in $1964^{[2]}$. Neodymium-doped yttrium aluminium garnet (Nd:YAG) was developed by scientists JE Geusic, HW Marcos and LG Van Uitert in 1964 and was used first for the control of gastrointestinal bleed. Dye lasers were discovered by physicists PP Sorokin and JR Lankard as well as FP Schafer et al., in $1966^{[3]}$.
Later, excimer lasers, copper vapour lasers and other lasers were discovered and continued to be added to the armamentarium of the treating doctors. The principle of selective photothermolysis was proposed in 1983 by Anderson and Parrish where they explained the process of selective destruction of certain tissues by absorption of a particular wavelength by a chromophore ${ }^{[4]}$. To standardise the practice of laser, many societies were established such as The Laser Institute of America, International Society for Laser Medicine and Surgery, American Society for Laser Medicine and Surgery, and The American National Standard Institute for the organisation and evolution of lasers.

\section{Facial laser surgery}

The use of lasers on the face has a very wide spectrum. They are amongst the most popular options in aesthetic practice for facial rejuvenation. They can also be used for the treatment of vascular and pigmented lesions, removing unwanted hair, treatment of facial scar and for the treatment of some dermatological disorders. We will discuss them in the article.

\section{Safety in laser surgery}

Safety in laser surgery is of paramount importance. It comes in the top priorities for any clinician. The Federal Laser Product Performance Standard classifies med- 
ical lasers on the basis of the ability to cause damage to ocular and cutaneous structures (Table 1). Class I laser does not cause damage. Class II lasers can cause ocular damage only if someone overcomes the natural aversion response towards bright light. Class III (mainly IIIb) lasers can cause ocular damage, and class IV lasers can be harmful to eyes and skin and has potential fire hazard.

Ocular hazard by long wavelength lasers $\left(\mathrm{CO}_{2}\right.$ and Erbium-doped yttrium aluminium garnet (Er:YAG)) can cause corneal burns. Holmium: YAG (Ho:YAG) laser can cause injury to the lens and cornea. It spares the retina. Short wavelength lasers can cause retinal damage ${ }^{[5]}$. Appropriate safety eyewear should be used for the protection of the eyes of all members who are inside the chamber where the session is going on. Fire hazard is associated mostly with the use of high power systems. Fire safety should be a priority inside the chamber. Fire extinguisher should be available near the laser room. The chamber should have restricted entry at the time of the procedure to avoid any accidental exposure.

Evacuation systems and ultra-low particulate air filter should be used to evacuate the plume and protective devices should be used by all members of the team.

International standards can be followed by observing the guidelines laid by the International Electrotechnical Commission for manufacturers, clinicians and administrators.

\section{Ethics statement}

The figures of the patients exhibiting various conditions are from the Department of Plastic and Maxillofacial Surgery, Government Medical College and Hospital, Nagpur, India. Informed consent was taken from the patients (or their parents, in the case of minor patients).

Table 1. Laser safety

\begin{tabular}{cl}
\hline Class of Laser & Safety profile \\
\hline I & Safe \\
II & $\begin{array}{l}\text { Safe but harmful if natural } \\
\text { aversion response to light } \\
\text { averted }\end{array}$ \\
III & Harmful to eyes \\
IV & Harmful to eyes, skin.
\end{tabular}

\section{Discussion}

\section{Laser for rejuvenation of the face}

The features of the aging face appear due to a combination of intrinsic and extrinsic factors ${ }^{[6]}$. These include wrinkles, malar depression, actinic changes, excess of skin, furrows, accumulation of submental fat and the showing of mandibular teeth. Sagging occurs due to the loss of skin elasticity, which decreases from an early age $^{[7]}$. Wrinkles (Figures 1 and 2) appear due to the decrease of procollagens I and III and collagen VII ${ }^{[8]}$. Fitzpatrick skin phototypes ${ }^{[9]}$ are used to classify the responses to sun exposure by the skin (Table 2). There are many lasers available for skin resurfacing. They can be used in the treatment of skin wrinkles, acne scars, actinic and seborrheic keratosis, photo-aging and lentigines. Table 3 summarises the different types of lasers.

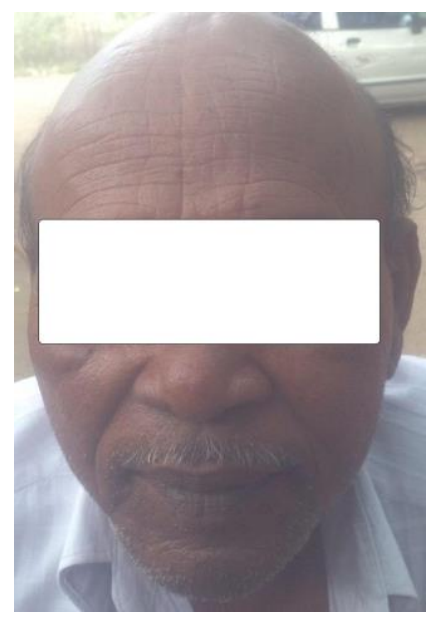

Figure 1. Aging face with wrinkles

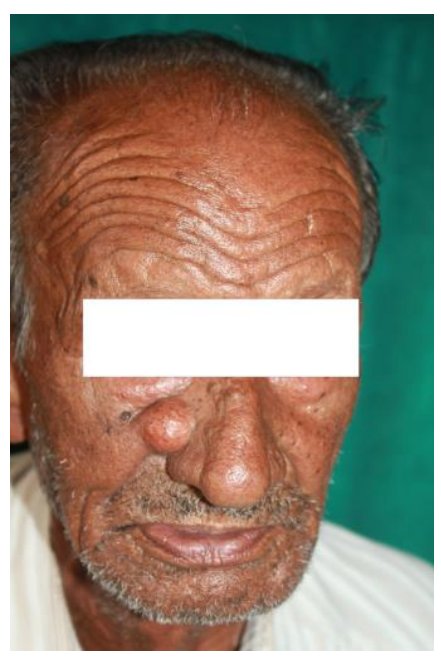

Figure 2. Aging face with wrinkles and lentigines 
Table 2. Fitzpatrick skin types

\begin{tabular}{llllll}
\hline Type & Scores & Skin colour & Effect to UVA & Reaction to sun & Skin tone \\
\hline I & $0-6$ & $\begin{array}{l}\text { Caucasian, blond/red hair, } \\
\text { freckles, fair skin, blue eyes }\end{array}$ & Very sensitive & $\begin{array}{l}\text { Always burns, } \\
\text { never tans }\end{array}$ & Very fair \\
II & $7-13$ & Caucasian & Very sensitive & $\begin{array}{l}\text { Usually burns, tans } \\
\text { minimally }\end{array}$ & Fair \\
III & $14-20$ & $\begin{array}{l}\text { Darker Caucasian, light } \\
\text { Asian }\end{array}$ & Sensitive & $\begin{array}{l}\text { Burns moderately, } \\
\text { tans uniformly }\end{array}$ & $\begin{array}{l}\text { Fair to } \\
\text { medium }\end{array}$ \\
IV & $21-27$ & $\begin{array}{l}\text { Mediterranean, Asian, His- } \\
\text { panic }\end{array}$ & $\begin{array}{l}\text { Moderately } \\
\text { sensitive }\end{array}$ & $\begin{array}{l}\text { Rarely burns, } \\
\text { always tans well }\end{array}$ & Medium \\
V & $28-34$ & $\begin{array}{l}\text { Middle Eastern, Latin, } \\
\text { light-skinned black, Indian }\end{array}$ & $\begin{array}{l}\text { Minimally sen- } \\
\text { sitive }\end{array}$ & $\begin{array}{l}\text { Very rarely burns, } \\
\text { tans very easily }\end{array}$ & $\begin{array}{l}\text { Olive or } \\
\text { dark }\end{array}$ \\
VI & $35-36$ & Dark-skinned black & Least sensitive & $\begin{array}{l}\text { Never burn, always } \\
\text { tans }\end{array}$ & Very dark \\
\end{tabular}

Table 3. Summary of lasers

\begin{tabular}{|c|c|c|c|c|}
\hline Laser type & Wavelength (nm) & Indications & Pulse duration (ms) & Complications \\
\hline $\mathrm{CO}_{2}$ & 10,600 & $\begin{array}{l}\text { Skin resurfacing, } \\
\text { wrinkles }\end{array}$ & 50 & $\begin{array}{l}\text { Edema, erythema, pruritus, contact } \\
\text { dermatitis, hyperpigmentation }\end{array}$ \\
\hline Erbium:YAG & 2940 & $\begin{array}{l}\text { Mild-to-moderate } \\
\text { rhytids, scars, pig- } \\
\text { mentation }\end{array}$ & .25 & Minimal burning \\
\hline Nd:YAG & $1064,1320,1440$ & $\begin{array}{l}\text { Wrinkles, pigmenta- } \\
\text { tion }\end{array}$ & 50 & Pain, redness, itching, swelling \\
\hline IPL & $500-1200$ & $\begin{array}{l}\text { Dyspigmentation, } \\
\text { wrinkling, telangiec- } \\
\text { tasia, hair removal }\end{array}$ & $1-300$ & $\begin{array}{l}\text { Erythema, discomfort, blisters, } \\
\text { pain, hyperpigmentation, crusting, } \\
\text { purpura }\end{array}$ \\
\hline PDL & 585,595 & $\begin{array}{l}\text { Vascular lesions, } \\
\text { wrinkling, dyspig- } \\
\text { mentation }\end{array}$ & 45 & Pain, purpura, swelling \\
\hline KTP & 532 & $\begin{array}{l}\text { Photo-damaged } \\
\text { red-brown discol- } \\
\text { ouration }\end{array}$ & $20-50$ & $\begin{array}{l}\text { Edema, pain, crusting, erythema, } \\
\text { telangiectasia }\end{array}$ \\
\hline Alexandrite & 755 & Tattoo, hair removal & 3 & Pain, redness, swelling, itching \\
\hline Diode & $600-1020$ & $\begin{array}{l}\text { Facial rhytids, telan- } \\
\text { giectasia, hair } \\
\text { removal }\end{array}$ & 30 & $\begin{array}{l}\text { Hyperpigmentation, erythema, } \\
\text { edema }\end{array}$ \\
\hline
\end{tabular}

\section{Ablative techniques}

This is more aggressive as compared to non-ablative lasers. $\mathrm{CO}_{2}$ laser $(10,600 \mathrm{~nm})$ vaporises the epidermis and dermis layer by layer. It rejuvenates the skin by epidermal regeneration and reorganisation, and by the strengthening of collagen bundles. It is more useful in severe facial wrinkles, challenging skin textures, and dyspigmentation $^{[10]}$. Fractional ablative lasers provide adequate skin resurfacing safely as compared to the unfractionated models used earlier. Non-ablative laser spares the epidermis, decreases fine wrinkles, chang- es the texture and tone of skin and treats dyspigmentation.

The scarring produced in continuous wave $(\mathrm{CW})$ laser is more when compared to the short-pulsed $\mathrm{CO}_{2}$ laser. Currently, high power pulse (ultrapulse) and $\mathrm{CW} \mathrm{CO}_{2}$ laser (acupulse) are used. The outermost layer of the epidermis and some part of superficial dermis are removed. Activated fibroblasts help in the deposition of collagen and elastin tissue ${ }^{[11]}$. The papillary dermis is affected to a minimum in newer lasers. The superpulsed lasers based on selective photothermolysis result in pure steam vaporisation and the adjacent tissue is affected 
minimally $^{[12]}$

Ultrapulse $\mathrm{CO}_{2}$ lasers for midfacial region are treated with $90 \mathrm{~mJ} / 45 \mathrm{~W}$ with first-pass density setting of 7 , and less for the upper and lower eyelids and even lesser for hairline and jawline. In the second pass, lesser density is required as compared to the first. Some wrinkles may require a third pass.

Postoperative period may be complicated with swelling (which subsides in a week), erythema, pruritus and contact dermatitis. Post-inflammatory hyperpigmentation, which occurs 2-3 weeks post-therapy, may be decreased with prior treatment of retinoic acid and hydroquinone ${ }^{[13]}$.

\section{Er:YAG lasers}

It has a wavelength of $2,940 \mathrm{~nm}$ with water as its chromophore. It is used for superficial rhytids, actinic keratosis, dyschromia and Favre-Racouchot disease ${ }^{[14]}$. The penetration and ablation is more superficial compared to $\mathrm{CO}_{2}$. About $10-20 \mu \mathrm{m}$ of thermal damage is caused by $10-40 \mu \mathrm{m}$ of skin impact. Skin tightening is achieved by the second and third pass. Wrinkles are reduced up to $50 \%$ in $2-3$ passes $^{[14]}$. Er:YAG has less crusting and erythema compared to $\mathrm{CO}_{2}$ laser ${ }^{[15]}$. Erbium can be combined with $\mathrm{CO}_{2}$ to give uniformity in the treatment of different areas of the face.

Fractional photothermolysis

It was developed by Relent technologies. The wavelength is $1,550 \mathrm{~nm}$. It is among the recent options for skin rejuvenation ${ }^{[16]}$. It treats only a fraction of skin. The thermal side effects are decreased.

\section{Non-ablative techniques}

These include plasma skin regeneration, pulse dye laser, $\mathrm{Nd}$ :YAG, intense pulsed light (IPL), light-emitting diode(LED) devices and photodynamic therapy. It involves the sparing of epidermis, and affects the dermis directly, which helps in early recovery. The mechanism is by targeting chromophores such as melanin, haemoglobin and collagen. The wavelength is in the visible to infrared region, targeting the upper and middle part of the dermis. There is the activation of dermal fibroblasts, which helps in healing.

Plasma skin regeneration

Nitrogen plasma delivers energy to the skin. There is no chromophore mediator and the energy is delivered in a uniform and smooth way to the dermis by pulses of plasma. It is a non-ablative method used to treat facial rhytids, benign facial skin lesions and actinic keratosis.

Pulse dye laser

Long pulse dye laser is used for the treatment of facial lentigines and wrinkles. There is no scarring or changes in skin pigmentation post-operatively ${ }^{[17]}$. There is an increase in dermal collagen with the use of $585-\mathrm{nm}$ pulsed dye laser (PDL) between days $0-90$ with maximum increase in the periorbital region ${ }^{[18]}$.

Intense pulse light

Dyschromia, ephelides, senile and solar lentigines can be treated with intense pulsed light (IPL) $)^{[19]}$. It is a non-coherent light with a wavelength between 500-1,200 $\mathrm{nm}$. It works on the basis of selective photothermolysis targeting haemoglobin, melanin and water. Skin tightening in IPL occurs due to the contracture of the heated collagen fibers. Photoaging due to telangiectasia and pigmentation shows significant improvement within three treatments ${ }^{[20]}$. Side effects include mild crusting, blistering, erythema and purpura, all of which are transient and self-limiting.

Potassium titanyl phosphate

The 532-nm lasers produce energy pulses with small spots. They target oxyhemoglobin and melanin. Patients with Fitzpatrick types I to III are good candidates for these lasers ${ }^{[21]}$. They are effective in treating photo-damaged red and brown discolourations. Side effects of the therapy include erythema and edema.

Light-emitting diode

Light-emitting diode (LED) was invented in 1962. It stimulates collagen synthesis and accelerates fibroblast-myofibroblast transformation. The wavelengths are 590, 633 and $830 \mathrm{~nm}$. For fine wrinkles, the periorbital area show more improvement than nasolabial $\operatorname{area}^{[22]}$. LED has shown to decrease erythema, edema, pain and bruising following blepharoplasty and periocular resurfacing by Er:YAG/ $\mathrm{CO}_{2}$ laser ${ }^{[23]}$.

\section{Near-infrared laser}

Rejuvenation with this laser is produced by long-lasting elastin stimulation. Significant improvement in the skin texture and wrinkles has been observed ${ }^{[24]}$. The increase in collagen and elastin improves skin texture, although without significant improvement in hyperpigmented lesions $^{[25]}$.

Photodynamic therapy

It involves use of light with photosensitising substance $(\delta$ amino levulonic acid). It has an additional advantage of destroying precancerous cells, in addition to the treatment of sun-damaged fine lines and pigmentation.

The more ablative the laser is, the better results it gives. This, however, comes at a cost of longer time of 
recovery for these patients. The fractional lasers provide the best combination to give optimal results.

\section{Treatment of pigmentation}

\section{Solar lentigines}

Though there are many topical therapies available, the treatment of solar lentigines by laser provides almost complete clearance. The options include Q-switched lasers, long-pulsed lasers and HGM K1 krypton lasers. Long-pulsed dye laser have shown near complete clearance of the lesion and reduced machine-produced index factor ${ }^{[26]}$. Q-switched Nd:YAG with 532-nm wavelength is a good option for light-skinned patients with lentigines, and $1064 \mathrm{~nm}$ for darker-skinned patients. Q-switched Nd:YAG is better than fractional $\mathrm{CO}_{2}$ laser for treating solar lentigines ${ }^{[27]}$.

\section{Solar elastosis}

$\mathrm{CO}_{2}$, Nd:YAG, diode, IPL and Er:YAG can be used for solar elastosis. Diode laser has the advantage of preserving the epithelial layer with resurfacing effects, same as that of $\mathrm{CO}_{2}$ laser ${ }^{[28]}$.

\section{Melasma}

Treatment options for melasma include:

1. Q-switched ruby laser

2. Erbium:YAG - refractory melasma

3. PDL - recurrent melasma

4. Fractional laser

5. IPL

Lasers should be used in patients of melasma who are refractory to topical therapies.

\section{Use of lasers in facial acne}

Potassium titanyl phosphate (KTP) laser may act through selective photothermolysis of the blood vessels or by a photodynamic effect on Propionibacterium acnes ${ }^{[29]}$. The 585-nm PDL has been used in treatment of acne scar ${ }^{[30]}$. It also decreases post-acne erythema. $1450-\mathrm{nm}$ diode laser and 1540-nm Erbium glass laser are also used for acne with the latter causing decreased oiliness.

They can be used in the inflammatory phase of acne by acting on haemoglobin and water as chromophores and for the management

\section{Laser for treatment of vascular lesions on the face}

\section{Hemangioma}

It is the most common type of vascular tumor (Figure 3).
Children should be treated when the hemangioma fails to regress. PDL with wavelength ranging from 585-600 nm with pulse width of about $0.45 \mathrm{~ms}^{[21]}$ can be used to treat these lesions. Residual scarring can be treated by $\mathrm{CO}_{2}$ or Erbium lasers.

Laser photocoagulation is the method of choice to treat port-wine stain. Argon laser can be used for the treatment of hypertrophied nodule of thickened port-wine stain. However, the disadvantage with Argon, $\mathrm{CO}_{2}$ and Nd:YAG is scarring ${ }^{[31]}$. Best results are with flashlamp-pulse dye laser ${ }^{[32]}$. Patients are treated at interval of 4-6 weeks or on clinical judgement.

\section{Venous malformation}

$\mathrm{Nd}$ :YAG can be used for deeper and superficial lesions with 595-1,064-nm laser (Figure 4).

\section{Lymphatic malformation}

Laser is useful in treating superficial lymphatic malformation of the head and neck area. 10,600-nm CO $\mathrm{CO}_{2}$ laser is of help for treating mucosal lesions.

\section{Facial telangiectasia and rosacea}

Vascular laser can be used to deal with facial telangiectasia. $\mathrm{CO}_{2}$ and Erbium:YAG can be used to treat rhinophyma (Figure 5). PDL remains the gold standard for the treatment of vascular lesions, though erythema and purpura may persist for a couple of weeks after treatment.

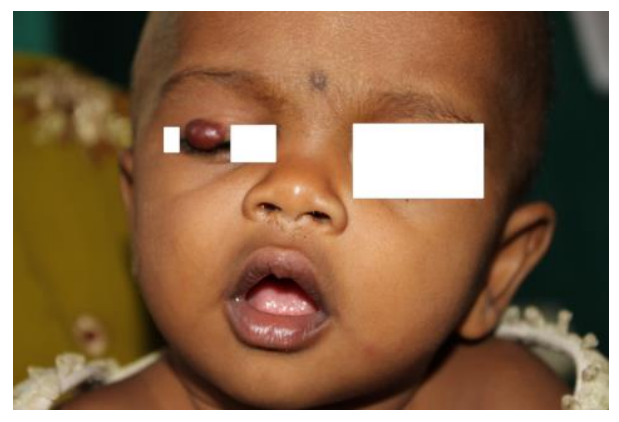

Figure 3. Hemangioma of the upper eyelid

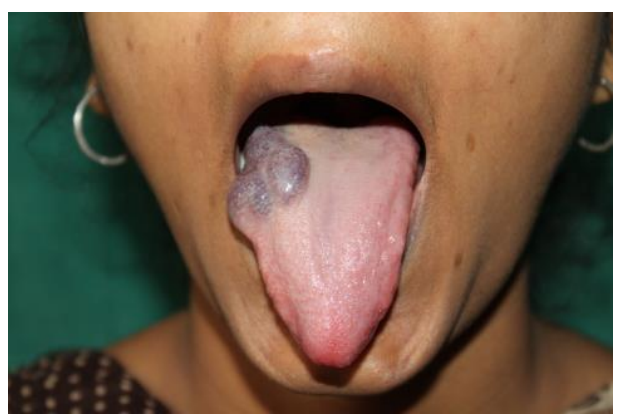

Figure 4. Venous malformation of the tongue 


\section{Laser for tattoo on the face}

Traumatic tattoos can be due to carbon, graphite, etc. They can be removed with Q-switch Alexandrite laser ${ }^{[33]}$. Tattoos applied by a professional are deeper and are more difficult to remove. Exogenous ink is the chromophore. Quality switch lasers have been used traditionally to treat these tattoos. Multiple settings are required for complete removal of pigments. The appropriate lasers for different colours of tattoo are as follows:

1. Black and dark blue pigment: QS ruby, QS $\mathrm{Nd}: Y A G(1,064 \mathrm{~nm})$ and QS Alexandrite ${ }^{[34]}$

2. Orange and red brown: 1064-nm QS Nd:YAG doubled in frequency

3. Red: Nd:YAG ${ }^{[35]}$

4. Green pigment: Alexandrite ${ }^{[35]}$

5. Purple and violet: Q-switched ruby laser ${ }^{[35]}$

6. Light coloured/pale: QS Alexandrite and QS $\mathrm{Nd}: Y A G$ laser ${ }^{[36]}$

7. Newer modalities:

a. Multi-pass treatment - multiple passes in one session ${ }^{[37]}$

b. Picosecond laser

Black, dark blue and red can all be removed with QS ruby, Nd:YAG and Alexandrite lasers.

\section{Laser for unwanted hair on the face}

Alexandrite $(755 \mathrm{~nm})$, diode $(800 \mathrm{~nm})$ and ruby $(694 \mathrm{~nm})$ lasers can be used to remove unwanted hairs on the face (Figure 6). Cutaneous hyper/hypopigmentation is more in these short wavelength lasers as compared to longer wavelength laser such as Nd:YAG (1,064 nm) laser. IPL and Q-switched Nd:YAG are other options for hair removal with good results.

Patients should be educated about the multiple treatment sessions and minor side effects such as itching, edema and redness after the procedure. People with higher Fitzpatrick skin types are more responsive to diode and Nd:YAG.

\section{Laser for facial scar}

Facial scars can be a result of trauma, post-surgery, post-burn or after any inflammatory process (Figures 7 and 8). Though many invasive and non-invasive treatment options are available, they are associated with recurrence, side effects, as well as failure rates.

\section{Specific lasers for different scars}

1. Post-burn scars: $\mathrm{CO}_{2}$ laser

2. Immature post-burn scar: Nd:YAG $(1,064 \mathrm{~nm})$
3. Fibrotic scar: Fractional laser

4. Hyperpigmentation and discolouration in post-burn scars: IPL and Q-switch

5. Hypertrophic scars ${ }^{[38]}$ : Nd:YAG $(1,064 \mathrm{~nm})$ and $\mathrm{CO}_{2}$

6. Post-traumatic scars ${ }^{[39]}$ : Erbium glass $(1,540$ $\mathrm{nm})$

IPL, PDL and Erbium glass $(1,540 \mathrm{~nm})$ have shown decent results.

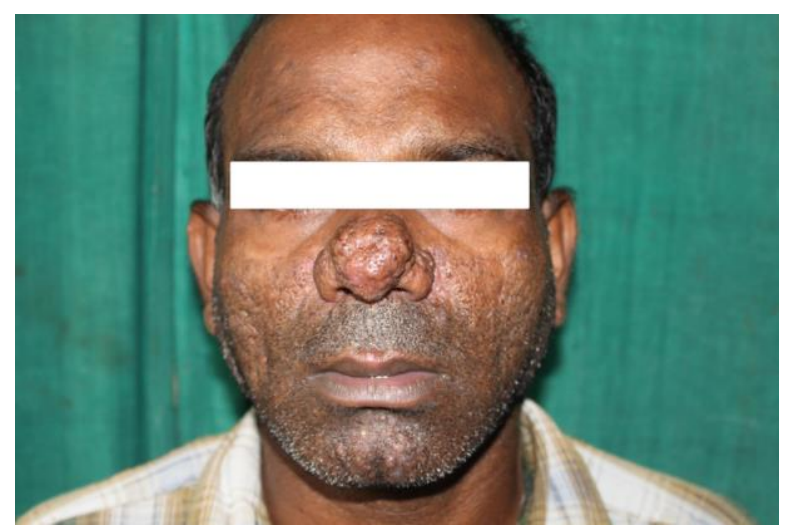

Figure 5. Rhinophyma of the nose

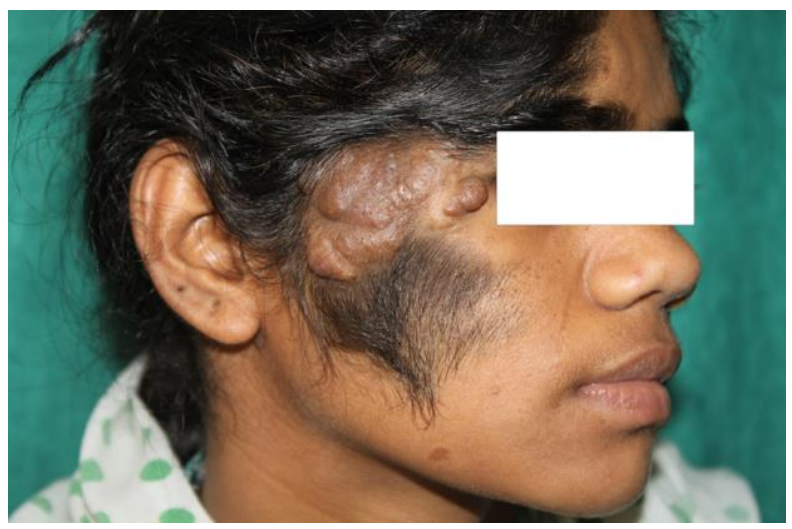

Figure 6. Black hairy nevus of the face

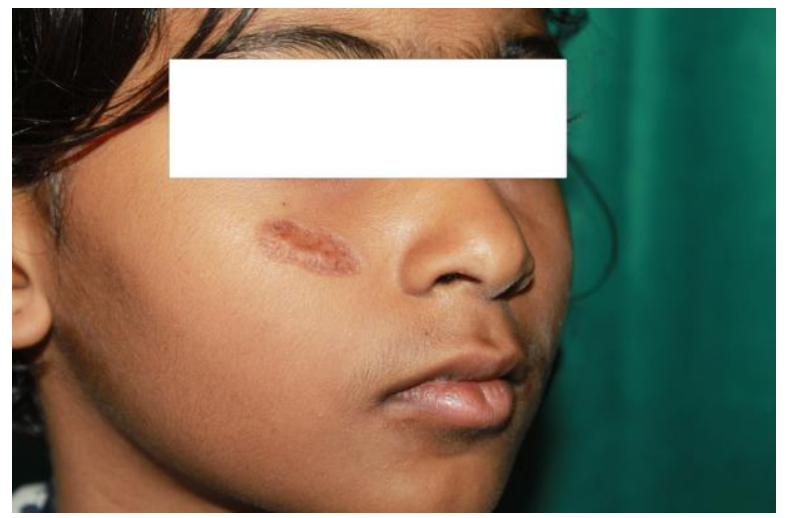

Figure 7. Post-traumatic facial scar 


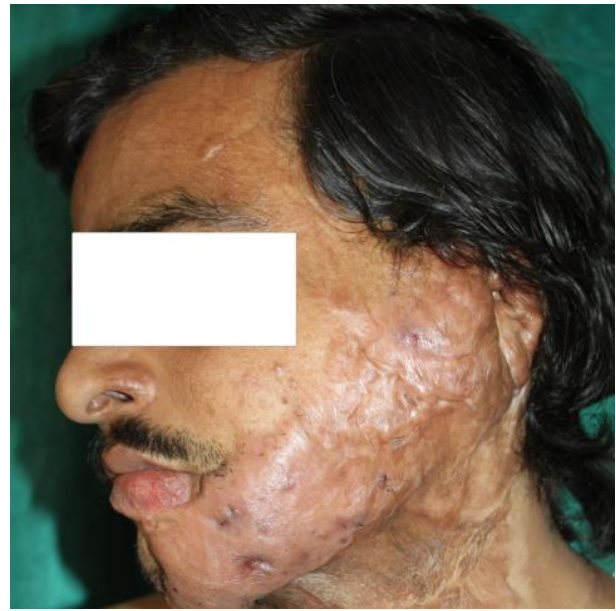

Figure 8. Post-burn hypertrophic scar on the face

\section{Lasers for cylindroma}

The Nd:YAG laser ${ }^{[40]}$ and $\mathrm{CO}_{2}$ laser ${ }^{[41]}$ can be used to treat cylindroma (Figure 9) in the head and neck region $^{[40,41]}$.

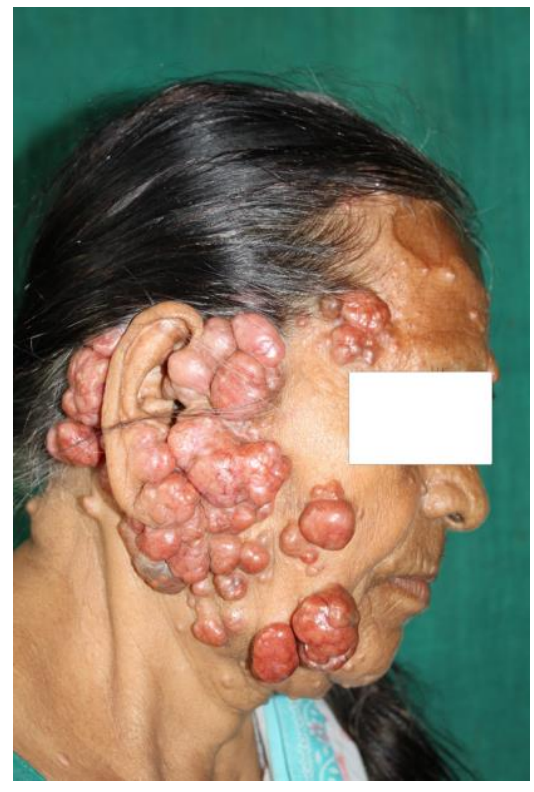

Figure 9. Cylindroma of the head and neck region

\section{Conclusion}

Lasers have become a powerful tool for many procedures on the face. Proper training of the care provider along with the staff and maintaining acceptable standards in the clinic makes the process safe. The risk-benefit ratio, the usefulness and the adverse effects of the procedure should not only be kept in mind at the time of procedure but are also explained to the patient and documented in detail prior to the procedure. The safety of medical personnel and the patient are of paramount importance and laser safety protocols should be followed every time the procedure is performed. Caution should be taken when evaluating the patient with unrealistic expectations.

\section{Author contributions}

Both S Harsh and SB Patil contributed to the drafting of manuscript.

\section{Conflict of interest}

The authors declare no potential conflict of interest with respect to the research, authorship, and/or publication of this article.

\section{References}

1. Shampo MA, Kyle RA, Steensma DP. Aleksandr Prokhorov-Laser and Masers. Mayo Clin Proc 2011; 86(5): e33. doi: 10.4065/mcp.2011.0194.

2. Omi T, Numano K. The role of $\mathrm{CO} 2$ laser and fractional CO2 laser in dermatology. Laser Ther 2014; 23(1): 49-60. doi: 10.5978/islsm.14-RE-01.

3. Sorokin PP and Lankard JR Stimulated emission observed from an organic dye, chloro-aluminum phthalocyanine. IBM J Res Develop 1966; 10(2): 162-163. doi: 10.1147/rd.102.0162.

4. Anderson RR, Parrish JA. Selective photothermolysis: Precise microsurgery by selective absorption of pulsed radiation. Science 1983; 220(4596): 524-527. doi: 10.11 26/science.6836297.

5. Smalley PJ. Laser safety: Risks, hazards, and control measures. Laser Ther 2011; 20(2): 95-106. doi: 10.5978/islsm.20.95.

6. Cevenini E, Invidia L, Lescai F, Salvioli S, Tieri P, et al. Human models of aging and longevity. Expert Opin Biol Ther 2008; 8(9): 1393-1405. doi: 10.1517/147125 98.8.9.1393.

7. Escoffier C, Rigal J, Rochefort A, Vasselet R, Leveque JL, et al. Age related mechanical properties of human skin: An in vivo study. J Invest Dermatol 1989; 93(3): 353-357. doi: 10.1016/0022-202X(89)90058-4.

8. Watson REB, Craven NM, Griffiths CE, Kang S, Jones $\mathrm{CJ}$, et al. A short term screening protocol, using fibrillin-1 as reporter molecule for photoaging. J Invest Dermatol 2001; 116(5): 672-678. doi: 10.1046/j.1523-1747.20 01.01322.x.

9. Treesirichod A, Chansakulporn S, Wattanapan P. Correlation between skin color evaluation by skin color scale chart and narrowband reflectance spectrophotometer. Indian J Dermatol 2014; 59(4): 339-342. doi: 10.41 03/0019-5154.135476. 
10. Preissig J, Hamilton K, Markus R. Current laser resurfacing technologies: A review that delves beneath the surface. Semin Plast Surg 2012; 26(3): 109-116. doi: 10.1055/s-0032-1329413.

11. Kauvar ANB, Geronemus RG. Histology of laser resurfacing. Dermatol Clin 1997; 15(3): 459-467. doi: 10.1016/S0733-8635(05)70454-X.

12. Bernstein LJ, Kauvar ANB, Grossman MC, Geronemus RG. Scar resurfacing with high-energy, short-pulsed and flashscanning carbon dioxide lasers. Dermatol Surg 1998; 24(1): 101-108. doi: 10.1111/j.1524-4725.1998.tb040 60.x.

13. Nanni CA, Alster TS. Complications of carbon dioxide laser resurfacing. An evaluation of 500 patients. Dematologig Surgery 1998; 24: 315-320.

14. Avram DK, Goldman MP. The safety and effectiveness of single-pass Erbium:YAG laser in the treatment of mild to moderate photodamage. Dermatol Surg 2004; 30(8): 1073-1076. doi: 10.1111/j.1524-4725.2004.30330.x.

15. Newman JB, Lord JL, Ash K, McDaniel DH. Variable pulse erbium:YAG laser skin resurfacing of perioral rhytides and side-by-side comparison with carbon dioxide laser. Lasers Surg Med 2000; 26(2): 208-214. doi: 10.1002/(SICI)1096-9101(2000)26:2<208::AID-LSM12> 3.0.CO;2-R.

16. Hamilton MM, Hobgood T. Emerging trends and techniques in male aesthetic surgery. Facial Plast Surg 2005; 21: 324-327. doi: 10.1055/s-2006-939512.

17. Kono T, Groff WF, Sakurai H, Takeuchi M, Yamaki T, et al. Comparison study of intense pulse light versus a long-pulse pulsed dye laser in the treatment of facial skin rejuvenation. Ann Plast Surg 2007; 59(5): 479-483. doi: 10.1097/SAP.0b013e3180327943.

18. Moody BR, McCarthy JE, Hruza GJ. Collagen remodelling after 585-nm pulsed dye laser irradiation: An ultrasonographic analysis. Dermatol Surg 2003; 29: 997-1000

19. Kawada A, Asai M, Kameyama H, Sangen Y, Aragane Y, et al. Videomicroscopic and histopathological investigation of intense pulsed light therapy for solar lentigines. J Dermatol Sci 2002; 29(2): 91-96. doi: 10.1016/S0923-18 11(02)00014-2.

20. Weiss RA, Weiss M, Beasley K. Rejuvenation of photoaged skin: 5 years results with intense pulsed light of the face, neck and chest. Dermatol Surg 2002; 28(12): 1115-1119. doi: 10.1097/00042728-200212000-00004.

21. Wall TL. Current concepts: Laser treatment of adult vascular lesions. Semin Plast Surg 2007; 21(3): 147-158. doi: 10.1055/s-2007-991183.

22. Baez F, Reilly LR. The use of light-emitting diode thera- py in the treatment of photoaged skin. J. Cosmet Dermatol 2007; 6(3): 189-194. doi: 10.1111/j.1473-2165.20 07.00329.x.

23. Trelles MA, Allones I. Red light-emitting diode (LED) therapy accelerates wound healing post-blepharoplasty and periocular laser ablative resurfacing. J. Cosmet Laser Therapy 2006; 8(1): 39-42. doi: 10.1080/14764170 600607731.

24. Tanaka Y, Matsuo K, Yuzuriha S. Objective assessment of skin rejuvenation using near-infrared 1064-nm neodymium: YAG laser in Asians. Clin Cosmet Investig Dermatol 2011; 4: 123-130. doi: 10.2147/CCID.S22841.

25. Lee JH, Roh MR, Lee KH. Effects of infrared radiation on skin photo-aging and pigmentation. Yonsei Med J 2006; 47(4): 485-490. doi: 10.3349/ymj.2006.47.4.485.

26. Ghaninejhadi H, Ehsani A, Edrisi A, Gholamali F, Akbari $\mathrm{Z}$, et al. Solar lentigines: Evaluating pulsed dye laser (PDL) as an effective treatment option. J Lasers Med Sci 2013; 4(1): 33-38.

27. Vachiramon V, Panmanee W, Techapichetvanich T, Chanprapaph K. Comparison of Q-switched Nd:YAG laser and fractional carbon dioxide laser for the treatment of solar lentigines in Asians. Lasers Surg Med 2016; 48(4): 354-359. doi: 10.1002/lsm.22472.

28. Muccini JA Jr, O’Donnell FE Jr, Fuller T, Reinisch L. Laser treatment of solar elastosis with epithelial preservation. Lasers Surg Med 1998; 23(3):121-127. doi: 10.1002/(SICI)1096-9101(1998)23:3<121::AID-LSM1>3 .0.CO;2-R.

29. Jih MH, Kimyai-Asadi A. Laser treatment of acne vulgaris. Semin Plast Surg 2007; 21(3): 167-174. doi: 10.1055/s-2007-991185.

30. Alster TS, McMeekin TO. Improvement of facial acne scars by the $585 \mathrm{~nm}$ flashlamp-pumped pulsed dye laser. J Am Acad Dermatol 1996; 35(1): 79-81. doi: 10.1016/S0190-9622(96)90501-0.

31. Dixon JA, Huether S, Rotering R. Hypertrophic scarring in argon laser treatment of port-wine stains. Plast Reconst Surg 1984; 73(5): 771-777. 10.1097/00006534-198405 000-00009.

32. Hsiao YC, Chang CJ. Update on flashlamp pumped pulsed dye laser treatment for port wine stains (capillary malformation) patients. Laser Ther 2011; 20(4): 265-272. doi: 10.5978/islsm.11-RE-01.

33. Moreno-Arias GA, Casals-Andreu M, Camps-Fresneda A. Use of Q-switched alexandrite laser (755nm, $100 \mathrm{nsec})$ for removal of traumatic tattoo of different origins. Lasers Surg Med 1999; 25(5): 445-450. doi: 10.1002/(SICI)10 96-9101(1999)25:5<445::AID-LSM12>3.0.CO;2-Q.

34. Leuenberger ML, Mulas MW, Hata TR, Goldman MP, 
Fitzpatrick RE, et al. Comparison of the Q-switched Alexandrite, Nd:YAG, and ruby lasers in treating blue-black tattoos. Dermatol Surg 1999; 25(1): 10-14. doi: 10.10 46/j.1524-4725.1999.08122.x.

35. Zelickson BD, Mehregan DA, Zarrin AA, Coles CC, Hartwig P, et al. Clinical, histologic, and ultrastructural evaluation of tattoos treated with three laser systems. Lasers Surg Med 1994; 15(4): 364-372. doi: 10.1002/1sm.19 00150406.

36. Fitzpatrick RE, Lupton JR. Successful treatment of treatment-resistant laser-induced pigment darkening of a cosmetic tattoo. Lasers Surg Med 2000; 27(4): 358-361. doi:10.1002/1096-9101(2000)27:4<358::AID-LSM9>3.0. CO;2-0.

37. Kossida T, Rigopoulos D, Katsambas A, Anderson RR.
Optimal tattoo removal in a single laser session based on the method of repeated exposures. J Am Acad Dermatol 2012; 66(2): 271-277. doi: 10.1016/j.jaad.2011.07.024.

38. El Taweel AI, Abd El-Rahman SH. Assessment of fractional CO2 laser in stable scars. Egypt J Dermato Venerol 2014; 34(1): 74-80. doi: 10.4103/1110-6530.137317.

39. Venkatram, George EP. Treatment of posttraumatic scar with ablative fractional erbium: YAG laser. Cosmetol \& Oro Facial Surg 2016; 2(1): 104.

40. Tarsted M, Molin L. Nd:YAG laser for effective treatment of multiple cylindroma of scalp. J Cosmet Laser Ther 2004; 6(1): 41-43. doi: 10.1080/14764170410030804.

41. Brooke-Spiegler syndrome: Treatment of cylindromas with CO2 laser. Dermatol Surg 2000; 26(9): 877-882 doi: 10.1046/j.1524-4725.2000.00 034.x. 